\title{
Tecnologia dos sonhos em Artemidoro, Freud, JUNG E NOS WARLPIRI ${ }^{\star}$
}

http://dx.doi.org/10.1590/1984-0292/1020

\section{Abrahão de Oliveira Santos ${ }^{\star}$, Tarso Ferrari Trindade}

Universidade Federal Fluminense, Niterói, RJ, Brasil

\begin{abstract}
Resumo
Apresentaremos distintas tecnologias dos sonhos: em Artemidoro, Freud, Jung e nos Warlpiri. Artemidoro revela a mensagem onírica imprescindível à condução do cidadão, com os elementos das instituições, da cidade, do cosmo. Com Freud, no moderno mundo europeu, o sonho recebe o sentido da interioridade. Outra leitura é de Carl Jung. O uso dos sonhos tem seu sentido histórico, se relacionando com as práticas de governo, os modos de condução da vida e da cidade. Para além das tradições eurodescendentes e mentalistas vigentes, apresentaremos a tecnologia coletiva dos sonhos dos Warlpiri e uma nova possibilidade de lidarmos com a experiência onírica.
\end{abstract}

Palavras-chave: imagem onírica; subjetivação; tecnologia dos sonhos; gestão dos sonhos; práticas de si.

\section{Technology of dreams in Artemidorus, Freud, JUNG AND WARLPIRI}

\begin{abstract}
We are going to present different technologies of dreams: Artemidorus, Freud, Jung and the Warlpiri. Artemidorus reveals the message of dreams essential to the citizen's conduct, with the elements of institutions, the city and the cosmos. With Freud, in the modern European world, the dream is given a sense of inwardness. Another interpretation is that of Carl Jung. The use of dreams has a historical aspect, as part of governance practices, and of ways of conducting life and the city. Beyond the still dominant Euro-descendant and mentalist traditions, we are going to present the collective technology of dreams of the Warlpiri and a new possibility to deal with the dream experience.
\end{abstract}

Keywords: dream image; subjetivation; technology of dreams; management of dreams; practices of the Self.

\footnotetext{
^ Financiamento da FAPERJ e PIBIC/UFF na forma de Bolsa de Iniciação Científica.

$\star \star$ Endereço para correspondência: Universidade Federal Fluminense, Departamento de Psicologia. Campus do Gragoatá, s/ nº, bloco O, $2^{\circ}$ Andar, Sala 218, Gragoatá. 24210350 - Niterói, RJ Brasil.E-mail: abrahaosantos@hotmail.com, tarsoesquizo@gmail.com
} 


\section{INTRODUÇão}

Há milênios, os sonhos ocupam o imaginário das pessoas e das ciências, que tentam dar-lhes sentido e estatuto. Inúmeras técnicas fulguram na história da humanidade, ao menos desde a Antiguidade Clássica. Sabemos que Alexandre, o Grande, tinha em suas fileiras reveladores de sonhos e segredos. Desses tempos, só a obra de Artemidoro de Daldis, do século II, permaneceu intacta. Tal obra, como veremos, aparece em diálogo oculto em muitas maneiras de entender a experiência onírica nos tempos atuais e também explicitamente com a moderna interpretação dos sonhos desenvolvida por Sigmund Freud, acompanhado por seus seguidores, inclusive o dissidente Carl Gustav Jung.

A experiência onírica tornou-se objeto das ciências psi, psiquiatria, psicossociologia, psicanálise, psicopatologia, saltando das místicas para as considerações clínicas, da expressão cósmica para a interioridade individual, do revelador de segredos para o analista. Faz mister observar o quanto os processos oníricos tornaram-se, no percurso temporal que se registra, parte íntima do sujeito, assunto privado pouco ou nada afeito ao campo social, político ou cósmico que portava anteriormente.

Nessa direção, procuraremos mostrar, por um lado, o uso dos sonhos proposto por Artemidoro, Freud e Jung em seu sentido histórico, melhor dizendo, como participa do contexto político e das questões sociais, ainda quando seus atores não o reconheçam. As tecnologias dos sonhos, vale dizer, as ferramentas e os modos de dar direção à vida ou resolver problemas provenientes de uma abordagem sistemática dos sonhos, contêm em si estreito consórcio com as práticas de governo vigentes, ou seja, os modos como devemos nos conduzir e conduzir a vida e a cidade. Por outro lado, mais distante das tradições eurodescendentes e mentalistas, temos a abordagem dos sonhos da tribo aborígene australiana chamada Warlpiri. Através do trabalho da antropóloga Barbara Glowczewski (1987), pudemos conhecer um modo distinto de conceber a relação entre os sonhos e os acontecimentos sociais, políticos. Distintamente das outras três metodologias, a tecnologia Warlpiri não tem autoria individual, mas é uma cultura milenar. Inspirados na prática dos Warlpiri, pretendemos um modo diferente de lidar com a experiência onírica.

Só mais dois pequenos aspectos à parte na incisão metodológica: vai ficar para outra vez a explicitação da inspiração foucaulteana que, o leitor vai perceber, não está oculta. Além disso, precisamos dizer que é a abordagem transdisciplinar que nos parece propícia. O sonho é, por excelência uma produção que articula várias dimensões do conhecimento: da clínica, da filosofia e da antropologia. Neste cruzamento de saberes podemos observar e compreender que certas questões dizem respeito a uma rede de entrelaçamentos políticos e sociais da existência da qual o indivíduo é um ponto. 


\section{A técnica de Artemidoro}

No século II, o grego Artemidoro de Daldis escreveu sua "onirocrítica" (ARTEMIDORO, 2009), relatando várias teorias sobre os sonhos e apresentando o desenvolvimento de sua arte da interpretação dos sonhos. Artemidoro redigiu seu livro para ensinar a técnica de prever o destino e guiar a conduta dos homens, seja aos intérpretes de sonhos, seja como um guia para às pessoas comuns ou manual de auxílio na gestão da vida cotidiana. Suas preocupações são o casamento, os percalços da vida e da morte, os empreendimentos, o enriquecimento, os filhos, enfim, as atividades a serem exercidas na cidade (ARTEMIDORO, 2009).

A onirocrítica se propunha, pela interpretação, a encontrar o verdadeiro sentido da imagem onírica e o real destino dos acontecimentos. Buscava oferecer ao seu leitor uma técnica, uma maneira de proceder para interpretar os signos dos sonhos; de decompor os sonhos em elementos e encontrar seu sentido. $\mathrm{O}$ ato de interpretar já aí se apresentava como procura da verdade oculta das coisas.

Os sonhos, para Artemidoro, são movimentos ou modelagem da alma, antecipando o bem e o mal que virão. Podem significar o futuro para aqueles que são capazes de ver, pois são feitos de "imagens particulares conforme a natureza das coisas" (ARTEMIDORO, 2009, p. 23).

O pensador grego faz uma classificação. Os sonhos simples não anunciam o futuro. São provocados por afetos que concernem ao corpo ou à alma e significam as coisas atuais. São efeitos simplesmente da lembrança da realidade presente. O apaixonado sonha que está com seu amado, o temeroso vê o que teme, o faminto, o que quer comer. Os sonhos simples dizem da realidade da alma, do seu estado atual, dos desejos. Falam dos indivíduos e seus efeitos se restringem à duração do sono.

Já os sonhos oníricos representam o futuro, falam dos acontecimentos do mundo e prenunciam o que virá. Estes "sonhos do ser" têm também influência depois do sono, pois anunciam o que vai acontecer e modificam a alma, oreinein, modelam-na. Sonhos oníricos são to on eirei, "o que diz o ser". Entre eles há os que se mostram claramente sem pedir deciframento ou que não comportam intervalo de tempo, pois o acontecimento sonhado logo se faz presente; são os chamados sonhos "teoremáticos". Por exemplo, uma pessoa sonha que recebeu dinheiro de um amigo e, no dia seguinte, recebe dez minas da parte dele.

Há também os sonhos "alegóricos", que significam uma coisa através de outras. Os acontecimentos se apresentam obscuramente; trata-se de um sonho sem transparência, que utiliza uma imagem para falar de outra e necessita ser interpretado. Nesta situação, a interpretação é útil. O tratado da onirocrítica vai se ocupar de como uma imagem representada no sonho pode anunciar um acontecimento porvir. Como na situação dos sonhos simples, os alegóricos também apresentam essa contiguidade com a realidade.

O onirocrítico, para melhor interpretar os sonhos, deve saber quem é o sonhador, seu ofício, sua origem, seu status social, sua fortuna, sua idade, seu sexo, e precisa examinar o sonho e seu conteúdo. A posição do sonhador e o conteúdo 
do sonho antecipam o que lhe acontecerá na vida real. Se um pobre sonhar que está "grávido", é sinal de que vai adquirir e acumular muitas riquezas, de modo a ficar inchado. Contrariamente, se for rico, passará por provações. Para uma jovem, sonhar que tem leite nos seios indica que vai produzir um fruto perfeito; para uma idosa e pobre, significa prosperidade; para uma mulher rica, prevê despesas. Para um homem necessitado de meios de sobrevivência, prevê superabundância de riquezas; para um atleta ou um gladiador, enfermidades, pois quem tem leite é o sexo frágil. Sonhar que tem crinas de cavalo significa escravidão e miséria para os bem-nascidos; para os escravos, confirma suas amarras, já que a crina do cavalo está sempre amarrada.

Como entende Artemidoro de Daldis, os sonhos antecipam o futuro relacionado ao sonhador, a um familiar ou a alguém próximo. São signos do porvir. Mas e quando o sonhador se vê pequeno diante da ordem da realidade apresentada no sonho, se vê como sem poder diante do desfecho onírico que diz respeito à cidade ou ao mundo? Há sonhos que se referem ao bem público, que está para além do círculo privado. São visões oníricas de coisas públicas, sonhos que trazem desfecho para todos os cidadãos. Não é um sonho de uma pessoa privada, de um particular, mas o sonho do "povo", do coletivo, e que é de interesse de todo cidadão. É justo e necessário que tais sonhos sejam levados ao conhecimento de todos. São os sonhos políticos, na nomenclatura de Artemidoro.

Além dos sonhos que dizem respeito aos acontecimentos da cidade, os sonhos com os astros, abalos sísmicos, maremotos, eclipses e fenômenos cósmicos também se incluem nessa categoria, evidentemente, pois não remetem ao homem privado das pequenas coisas, mas ao bem público e de interesse de todos. É importante frisar que as pessoas não representam as próprias pessoas, necessariamente. Um ferreiro que aparece em sonho de outro ferreiro pode referir-se à fundição.

A leitura da "onirocrítica" de Artemidoro não nos deixa dúvidas de que o sonho liga-se impreterivelmente ao sonhador. "Nunca teremos sonhos a respeito de coisas que nunca nos preocupam, já que mesmo quando se trata de nossos próprios problemas, se não nos preocupamos não sonhamos com eles" (ARTEMIDORO, 2009, p. 26). Mas as variações oníricas são largas e essa noção de "preocupação" é pouco definida. Parece-nos que Artemidoro coloca aí a relação do sonho com o ser social do sonhador, isto é, com sua relação com os destinos da pólis. A divisão que vai dos sonhos pessoais e de afeto aos sonhos cósmicos pode nos permitir adotar a ideia, um pouco além de Artemidoro, mas não fora do seu sistema, de que não é absolutamente necessário que o sonho seja referido ao sonhador.

O sonho como modelagem da alma, expressão da verdade do ser, to on éirei, relaciona-se aos fenômenos cósmicos ou aos acontecimentos da natureza, aos fenômenos da cidade, ou do que vai acontecer a outra pessoa próxima ou distante. Afirmar que o sonho modela a alma e que - to on éirei - diz do ser, não é restringi-lo à interioridade da alma, pois ele expressa transformações nas pessoas, na cidade, na natureza das coisas e no cosmos. 
Nessa tradição, a interpretação enuncia o que há de vantajoso ou temeroso para o sonhador, o que vai lhe acontecer, pressagia o destino do sonhador na vida social. ${ }^{2} \mathrm{O}$ sonho faz previsões por meio das alegorias que devem ser decifradas pelas analogias que o onirocrítico encontra, comparando as semelhanças das imagens da noite com as da vigília. A claridade do dia confirma a verdade trazida na dramática onírica. Ou podemos entender que a realidade do sonho tem uma estruturação homogênea com a realidade do dia claro, ou entendemos que a realidade se estende até o universo noturno e lá se apresenta antecipando-se. A interpretação não se volta para uma curiosidade pessoal, mas é um trabalho para "gerir a própria existência", no feliz comentário de Foucault (2009, p. 184) e preparar para os acontecimentos do futuro.

Como as noites dizem o que os dias serão, o dono de casa e pai de família precisa saber decifrar as imagens oníricas a fim de bem conduzir a própria existência. Por isso, as analogias dos sonhos trazidas por Artemidoro se dão no contexto da vida familiar, econômica e social nos quais se projetam. Assim a importância evidente das semelhanças e analogias entre o sonhador e o sujeito personagem da cena onírica, bem como de todos os elementos da cena com os elementos do drama social vígil. A leitura das analogias procede ao encontro do modelo social. A interpretação não se volta para o interior do sonhador, nem o imaginário ou subjetivo, mas para as circunstâncias concretas de vida da pólis. Não há sentido psicológico no sonho, tal como não é ele expressão subjetiva, mas antes desenvolvimento cósmico que afeta o sonhador, sua família e sua cidade.

O universo noturno é percebido como uma extensão da cena social na suposição de consubstancialidade do social e do onírico. No contexto da cosmovisão grega, há conexão imediata entre homem, cidade e cosmos. Artemidoro não destaca única e exclusivamente o passado do sonhador, nem mesmo suas paixões, pois vê no sonho o traçado do social, observando-o em relação à natureza das coisas, às instituições, às leis e aos costumes, à forma dos corpos, à quantidade, aos ofícios, às doutrinas, entre outros.

Provocados pelos afetos, lembranças das realidades presentes - ou anúncio do futuro - , os sonhos em Artemidoro estão em coalescência com a realidade, ou, o que seria melhor dizer, com a experiência concreta do ser da cidade e da história. A conexão entre homem, cidade e cosmos era imediatamente percebida pelos gregos antigos, que viam uma fusão das fronteiras do sonho, do acontecimento do mundo exterior e do espaço religioso. Pela semiótica do mundo grego antigo, entre as imagens dos sonhos e a realidade, atual ou futura, há um nexo natural. O sentido do sonho é encontrado pelo onirocrítico nas semelhanças com o espaço social, neste incluindo as instituições, digo, leis e costumes, sagrado e cósmico. De modo algum a interpretação se firma a partir de uma subjetividade, de uma interioridade, mas se volta para a o ser, que na Grécia Antiga era determinado pela exterioridade do seu lugar na pólis.

Signos da realidade ou dos acontecimentos futuros, mesmo quando a imagem onírica anunciava o inevitável, era importante conhecer antecipadamente o que ia acontecer. Os sonhos são assim, profeta e conselheiro, e era necessário que 
homens e mulheres, jovens e velhos, ricos e pobres se aplicassem na técnica de interpretá-los. A análise dos sonhos fazia parte das técnicas de existência e práticas de si, que se desenvolveram no plano da reflexão filosófica e ética de maneira acentuada nos séculos I e II. Uma visão racional da vida deveria empenhar-se em decifrar as imagens oníricas, seja com esforços próprios, seja com a ajuda dos profissionais das imagens da noite, como se referia Foucault (2009). Desde o século IV a. C., no cotidiano do mundo grego, as práticas de si já haviam se difundido antes mesmo de qualquer reflexão filosófica e obtiveram grande desenvolvimento nos séculos I e II, inclusive no Império Romano. Diziam respeito a modos de os indivíduos formarem-se e se transformarem, de sentirem orgulho de si, de se sentirem contentes consigo mesmos, enfim, de atingirem para si uma verdade e de se conduzirem como se deve na vida.

\section{A tecnologia dos sonhos de Freud}

O impacto do livro de Sigmund Freud (1987[1900]), A Interpretação dos Sonhos, na abordagem moderna dos sonhos, é evidente. Publicado em 1900 e tido como marco fundador da psicanálise, a partir dele uma nova terapêutica para o sofrimento humano se firma e o domínio sobre as profundezas do espírito e a loucura ganham uma consistência não vista até aquele momento no solo europeu liberal. Os sonhos, memória a ser reconquistada, são recolocados no campo das significações e da dimensão psicológica. A tecnologia dos sonhos de Freud torna-se o método no qual o mais fundo da alma, o escondido, as forças arcaicas indomáveis, secretas e transgressivas são perscrutados e revelados. Com a consistência e eficácia que o gênio lhe deu, a psicanálise tornou-se autoridade na interpretação do segredo dos homens, determinou os diagnósticos daqueles que, pela experiência subjetiva que apresentavam, ficaram à margem da circulação urbana e as condutas na psiquiatria por décadas e tornou-se quase um lugar-comum no modo de ver as chamadas doenças do espírito no campo da assistência à saúde mental no Brasil.

O sonho, na psicanálise, tem sua razão de ser no cotidiano privado dos indivíduos e o objetivo da análise é reinseri-lo no contexto da vida anímica (FREUD, 1987[1900]). O deslocamento de interesses cegos e intenções desenfreadas, sem limites e hostis à cultura, para as representações imagéticas oníricas permite, segundo a leitura do fundador da psicanálise, que tais moções sejam elaboradas, relativizadas, refreadas e tornadas adequadas ao liame social. A vida noturna é o espaço de arrefecimento necessário ao controle dos instintos para que a civilização seja mantida. É no nível representacional, simbólico, que se garante a inscrição dos indivíduos e seus imperativos instintuais na convivência urbana. O sonho é o lugar do segredo recalcado e do privado, no qual as forças destrutivas da civilização ganham reserva. É esse recalque e outras distorções capazes de impedir o trabalho de compreensão do analista (FREUD, 1987[1900]) que a interpretação vem superar. Esta procura as chaves semânticas ou gramaticais do sentido das imagens e da revelação dos sintomas, das repetições traumáticas, das cenas infantis dos fantasmas (LAPLANCHE; PONTALIS, 1988) que insistem 
em ocupar inadequadamente o meio urbano adulto. O doente nada mais é do que uma criança que não cresceu e vive em estado infantil. É a margem inassimilável das subjetividades urbanas da Europa moderna.

Todo sonho tem seu ponto de partida em pensamentos despertados nos dilemas e conflitos pessoais do dia anterior. As impressões da vigília recebem o investimento de uma moção psíquica infantil, um desejo recalcado, incestuoso, cuja realização se dá simbolicamente (FREUD, 1987[1900]). O sonho é a satisfação de desejos disparados na vigília, mas frustrados; representam vontades inconfessáveis, um "estado de coisas específico, tal como eu desejaria que fosse" (FREUD, 1987[1900], p. 138). Desejos dos quais o sujeito se envergonha, não tem coragem de apresentá-los ou de reconhecê-los; são vontades imperceptíveis que, durante o dia anterior, não tiveram lugar.

Nessa cena mentalista tal qual Freud a vê, não há processo de invenção, nem produção de algo novo ou específico do processo onírico, pois sempre se representa um "estado de coisas" de um sujeito. E não é por outro motivo que ele pode representar algo que está estabelecido, embora não sabido pelo sujeito. Não pode haver a criação (FREUD, 1976[1922]), nem o novo ou o imprevisto. A imagem onírica porta sempre a reapresentação do que lá já estava há muito tempo. $\mathrm{O}$ mentalismo aí configura uma cisão entre a imagem e seu significado. Aquilo que dá vida ao sonho - a moção desejante, o pensamento onírico - é exterior à imagem que se apresenta. O pensamento onírico e a moção são inconscientes e para sempre apartados do sujeito que sonha. Essa condição vem já dos pressupostos desde Leibniz, para quem as associações de imagens se conservam na alma mantidas por um pensamento que as organiza de modo inconsciente. Tal pensamento é inacessível ao sujeito e cabe ao intelecto formulá-lo (SARTRE, 2010).

A narrativa em imagens, o sonho manifesto, subsome um pensamento inconsciente que a organiza. Tem nessa raiz a noção, para Freud, de que o sonho "não é nunca criador" (FREUD apud LAPLANCHE; PONTALIS, 1988, p. 143; FREUD, 1976[1922], p. 258). Não se desenvolveu na psicanálise freudiana um conhecimento da imagem onírica como um acontecimento próprio, nem mesmo quando Freud se aproxima do construtivismo de "Construções em análise" (FREUD, 1975[1937]), no final de sua vida. Nele, toda construção mental permanece ligada à ficção biográfica como estrutura de uma lembrança.

Em confluência com as emergências políticas e culturais da Europa na época, a teoria da realização onírica do desejo infantil reduziu o sonho inteiramente à dimensão psicológica. Via de acesso privilegiada à verdade da alma que será, uma vez trazida à luz, reconectada à estrutura familiar e aos valores da sociedade e reequilibrada. Impossibilitado de dar conta do que lhe acontece desde sua interioridade, todavia articulado com os valores da cidade, o sujeito só é capaz de reencontrar-se com sua verdade quando esta lhe é devolvida pelo psicanalista. $\mathrm{O}$ sujeito não tem acesso ao sentido dos seus sonhos. O sonho, na psicanálise, repete eternamente a inscrição das matrizes nas quais toda a experiência se contém e se constitui, como o relógio na parede da fábrica que marca o mesmo tempo independentemente da forma histórica da existência. A técnica de interpretação busca 
na expressão onírica os determinantes das ideias, dos impulsos inconscientes, dos significados da imagem. Ela nos dá o ponto de apoio a partir de onde recebo do interpretador a verdade do meu desejo. Assim o sonho, submetido à autoridade do sonhador, é privatizado no mesmo golpe, pois surge como realidade individual, como informante de uma verdade sobre o sujeito, que lhe dá, a partir de fora, a ilusão de ser a soberania de suas intenções e do sentido do que deseja. Trata-se de expurgar o que Foucault chamou de "desatino do mundo" (FOUCAULT, 1989, p. 14), que aparece nos indisciplinados e nos escorraçados da cidade.

$\mathrm{Na}$ formação do homem civilizado europeu, sua suposta liberdade "original" é má, recalcitrante e injusta por natureza e cabe à sociedade dominá-la e torná-la útil. Os indivíduos necessitam gerir adequadamente seus instintos, suas derivas, sua agressividade, seu poder de contestação ou sua libido no reino complexo da sociedade que tornou, no governo liberal, cada um isolado em si mesmo. Liberado o "sem-comunidade", o indivíduo cujo mundo foi subtraído, a gestão da cidade o lança em uma lógica de interesses sempre individuais e faz disso o parâmetro de toda a vida. E é segundo tal lógica que todos e cada um devem satisfazer seu desejo, ou seja, conseguindo colocá-lo em circulação, mas sem pôr em risco os valores do que os europeus entenderam chamar de civilização.

O espaço psicológico como parte da gestão dos impasses da cidade foi constituído por um longo processo histórico-político na Europa dos séculos XVI ao XIX (FIGUEIREDO, 1994), primeiro como produção de uma individualização e da razão interior dos conflitos humanos no Estado, depois daí derivaram diversos projetos psicológicos. Na era moderna, as pessoas são instadas a esconderem-se umas das outras e de si mesmas, bem como suas funções corporais e seus desejos instintivos (ELIAS, 1994). Na opinião de Norbert Elias, essa privatização instala ao seu lado uma angústia distribuída no espaço social, talvez no próprio ato desse isolamento de si, dessa consciência de si que se inicia com o renascimento europeu. O indivíduo fechado em si é tomado da angústia de existir como ser destacado, o homem urbano acossado pelos confrontos dos interesses sociais dados pela diretriz burguesa. Compartilhar os afetos de que sofremos, nossos segredos mais noturnos, tornou-se um sinal de fraqueza, de uma individualização incompleta que denuncia no adulto elementos infantis. O mentalismo inspirado no romantismo e no liberalismo, parte das estratégias de gestão do urbano, é, naturalmente, anterior a Freud. Não obstante, é um dos matizes da constituição de sua tecnologia, incluindo aí o modo de trabalhar os sonhos pela via interpretativa.

\section{A tecnologia dos sonhos de Jung}

$\mathrm{Na}$ abordagem da psicologia analítica, a importância terapêutica também surge como motivo principal do estudo dos sonhos. Para Jung (1999), a interpretação dos sonhos se justifica exatamente pela possibilidade de tratamento das neuroses, também no contexto da consideração individualista do século XX europeu. Há, no entanto, importantes diferenças em relação ao método e às concepções de Freud. Primeiramente, não há distinção entre conteúdo manifesto e conteúdo latente. De acordo com Jung (2002), ao comunicar coisas à consciência 
o sonho se utiliza de imagens, de símbolos e, por isso, ele pode parecer incompreensível. Não há sentido oculto detrás da imagem onírica; ela contém seu sentido por inteiro naquilo que aparece (JUNG, 1999). O método de Jung reside, assim, na investigação da própria imagem onírica.

A segunda diferença em relação à psicanálise refere-se ao sentido da experiência onírica. Jung não nega que os sonhos possam ser realizações de desejo, contudo, eles não possuem apenas esse sentido. Na psicologia analítica, o sonho é polissêmico, ou seja, possui inúmeros sentidos possíveis (e alguns dos quais dificilmente podemos acessar). De acordo com o autor, "os sonhos podem exprimir verdades implacáveis, sentenças filosóficas, ilusões, desenfreadas fantasias, recordações, planos, antecipações, e até visões telepáticas, experiências irracionais e sabe Deus o que mais" (JUNG, 1999, p. 19). É a tentativa sabidamente vã de Jung de dar uma classificação para as possibilidades ilimitadas ou infinitas do onirismo.

Toda interpretação de sonhos também depende do conhecimento do contexto de vida e da situação consciente do sonhador. Por exemplo, há sonhos de início de tratamento que podem servir como diagnóstico para o analista, pois indicam a etiologia de uma neurose e até mesmo podem apontar o curso a ser seguido na análise (prognóstico). Há na psicologia analítica uma preocupação não apenas com a origem do sonho ou suas causas ou o seu "porquê", mas principalmente com a finalidade daquele sonho naquele momento de vida do sonhador, o seu "para quê" (JUNG, 1999).

Assim sendo, daremos um exemplo, de maneira ilustrativa, para mostrar como a psicologia analítica trabalha com os sonhos. Suponhamos que um paciente sonhe com uma fogueira. $\mathrm{O}$ analista deverá amplificar ao máximo possível tal imagem, solicitando do sonhador todos os detalhes do sonho, como o material que serve de combustão, a cor do fogo etc. Também pedirá que diga tudo o que sabe sobre fogueiras, ou seja, que representações ele possui delas, as experiências que teve com as mesmas e outras informações sobre tal assunto. Junto a isso, o analista deve ele próprio conhecer a respeito dos diversos símbolos presentes em religiões, mitos, folclores e demais fontes culturais coletivas, pois alguns símbolos ou imagens oníricas podem remeter não somente à história pessoal do sonhador, mas à história, tradição e cultura de uma dada coletividade. A esse processo de multiplicação dos inúmeros possíveis significados das imagens do sonho os seguidores de Jung deram o nome de amplificação (MAIA NETO, 2010). Em sua teoria, Jung não nomeia tal procedimento, utilizando muitas vezes o termo interpretação ou outros de forma equivalente. Por este motivo, e para diferenciar tal método daquele empregado pela psicanálise, seus alunos decidiram por emprestar um nome distinto.

Dessa maneira, a atribuição do significado aos sonhos ou a construção de um sentido para os mesmos advém de um processo onde terapeuta e paciente exploram juntos uma gama de significados que vão desde aspectos coletivos até individuais, próprios do paciente (e vice-versa). O que vai determinar, de fato, o sentido de um sonho em um dado momento, é a situação consciente do indivíduo e sua capacidade de significar tais experiências no presente. Ao abordar o mesmo 
sonho em um momento posterior, o sentido que lhe é atribuído pode ser inteiramente distinto. De acordo com Jung $(1999$, p. 27), um símbolo representa "uma grandeza desconhecida, difícil de reconhecer e, em última análise, impossível de definir" em termos precisos e absolutos. Nesse ocultismo, um elemento da experiência repousa misteriosamente inacessível.

Em decorrência disso, na tarefa de interpretação de sonhos, é importantíssimo trabalhar com séries de sonhos. Dificilmente um sonho isolado e obscuro pode ser interpretado corretamente e com segurança. No entanto, ao analisarmos vários sonhos em sequência, as interpretações posteriores vão ajudando a corrigir as análises dos precedentes; "também é na série de sonhos que conteúdo e motivos básicos [inconscientes] são reconhecidos com maior clareza." (JUNG, 1999, p. 21).

Basicamente, esses são os principais postulados acerca da abordagem dos sonhos na psicologia analítica. Passemos agora à sua análise crítica vista do prisma político e do contexto social de sua época. É digno de nota que tal tarefa não é algo simples. O caso de Jung é um tanto quanto emblemático. Há poucos artigos e escritos sobre esse tema ou mesmo sobre sua teoria de uma forma geral. Pesquisando no portal de buscas de artigos SciELO, observa-se uma quantidade mínima de textos sobre psicologia analítica. Tal achado não é surpreendente, visto que, como afirma Samuels (2002, p. 27) na introdução do livro Manual de Cambridge para estudos junguianos, “Jung foi 'completamente banido' da vida acadêmica". Os textos que discutem criticamente a abordagem da psicologia analítica têm surgido nos últimos tempos e só recentemente (menos de cinquenta anos) é que outros pesquisadores de distintas áreas do conhecimento têm se interessado pelas teorias de Jung (SAMUELS, 2002). Não obstante, ainda assim é possível fazer algumas asserções ao nosso tema em questão.

A atmosfera dos primeiros escritos de Jung assemelha-se em muito àquela em que Freud criou e desenvolveu a psicanálise. Embora o segundo fosse vinte anos mais velho e Jung tenha vivido até 1961, vendo assim a Segunda Guerra Mundial e o início da Guerra Fria, ambos estavam inseridos no mesmo espírito de época. Em um dos capítulos do Manual de Cambridge, Claire Douglas (2002) aborda o contexto histórico da psicologia analítica não pelo viés dos acontecimentos da época, mas pelas influências dos pensamentos artísticos, científicos e filosóficos daquele momento que tiveram forte impacto no pensamento de Jung.

Tanto Freud quanto Jung foram muito influenciados pelo romantismo alemão e sua visão da condição trágica humana: suas ideias de um lado bom e um lado mau do homem, a possibilidade de irrupção dos instintos, do mais bestial contrastando com os avanços da civilização, a capacidade de criação artística e científicas as mais sublimes (DOUGLAS, 2002). Nesse sentido, naquela época, dá-se uma ênfase muito grande aos estudos das ciências do homem, mas principalmente focando o ser humano enquanto indivíduo e sua natureza íntima. Por isso as pesquisas sobre as profundezas da mente, o lado sombrio e irracional da humanidade e, portanto, uma concepção de subjetividade privada, personológica e centrada na mente. De 
acordo com Douglas (2002, p. 43), essa diretriz "voltava-se para o irracional, para a realidade interior individual e para a exploração do desconhecido e enigmático, quer no mito, nos domínios antigos [...] ou nos estados alterados da mente".

Há toda uma movimentação das pesquisas e das ciências que, de um ponto de vista, se consagra a dar claridade aos fenômenos políticos, sociais, culturais e humanos, e, de outro, um ocultismo obsedado que persiste em manter-se preocupado com um elemento inexplicável da experiência, como a justificar a permanente vigilância que os doutores devem manter sobre todos os acontecimentos. O enigmático que surge intempestivamente e ameaça a civilização europeia. As ciências empenham-se em localizar, isolar e neutralizar essas forças "naturais" preservadas no indivíduo. Freud e Jung deram primazia ao indivíduo e suas transformações pessoais, sendo a sociedade (o mundo externo) e seus movimentos puras extensões onde se reeditam os processos desenvolvidos na mente no mundo interno. Totem e Tabu, de Freud (1912), e Ensaios sobre Acontecimentos Contemporâneos, de Jung (1946), citado por Alschuler (2002), são textos que tratam dessas reedições. O coletivo ou as massas para ambos os autores têm uma conotação negativa, irracional, fonte de fortes e incontroláveis instintos e afetos, demandando certa ordenação ou liderança sob o comando do conhecimento.

O campo social e político em ambos estão intimamente ligados ao projeto burguês de sociedade da Europa vitoriana. Conforme Alschuler (2002), nas análises políticas de Jung o indivíduo e as funções do líder político ganham a atenção do conhecimento sobre o movimento das massas. Os movimentos político das massas não são compreendidos. Os dirigentes e os intelectuais europeus, guiados pelas tecnologias das classes burguesas liberais, assustados com a reação das populações, necessitam urgentemente desqualificar as revoltas, as lutas, os conflitos urbanos, individualizar os conflitos e patologizar as turbulências políticas.

Como não poderia deixar de ser, tais urgências ressoam nos postulados e nas práticas da psicologia analítica. As questões políticas e sociais em Jung aparecem quase todas como tributárias do modo como a psique se expressa no mundo. Em outras palavras, os problemas encontrados na sociedade têm suas causas e soluções no psiquismo dos indivíduos. Durante a Guerra Fria, por exemplo, Jung entendia a divisão do mundo entre Ocidente e Oriente a partir da divisão interna da psique. A solução para tais embates seria a integração desses opostos e o reconhecimento das projeções feitas entre um e outro. Segundo Alschuler (2002, p. 262), "Jung afirma que o único portador da vida é a personalidade individual e que a sociedade e o Estado são ideias que só podem ter realidade como aglomeração de indivíduos". Para que haja transformações sociais, é preciso que o indivíduo primeiro transforme a si mesmo. Em se tratando dos sonhos, o mesmo raciocínio está posto, a experiência onírica não é vista para além do mentalismo individualista.

Nesse ponto, uma ressalva: a formulação do inconsciente coletivo, uma instância que indica na experiência onírica conteúdos para além das vivências ou história pessoal de um indivíduo, indica uma abordagem mais social dos sonhos. Ao se deparar com certos materiais oriundos principalmente dos sonhos e delírios, Jung observou algumas imagens totalmente desconhecidas de seus 
pacientes e não pareciam em nada corresponder ou ter qualquer tipo de relação com o contexto de vida pessoal deles (JUNG, 2002). Eram imagens arcaicas, símbolos presentes em culturas e religiões diversas com os quais aquelas pessoas jamais haviam entrado em contato antes. A partir disso, ele começou a elaborar a hipótese de que o inconsciente poderia ter "um objetivo situado além da pessoa humana" (JUNG, 2002, p. 9).

Diferenciando duas instâncias inconscientes, uma nomeou de inconsciente pessoal, cujos conteúdos seriam de natureza pessoal porque se caracterizariam por aquisições derivadas do passado da pessoa, de suas vivências individuais e poderiam ser reconhecidos em suas manifestações. A outra instância ele denominou de inconsciente coletivo, cujos conteúdos são da ordem do impessoal, de uma dada coletividade, ou seja, dizem respeito à comunidade humana em geral. Trata-se, nas palavras do autor, "não de ideias inatas, mas de caminhos virtuais herdados" (JUNG, 2002, p. 13). Os sonhos cujas imagens são de natureza coletiva referem-se a problemáticas coletivas, questões que dizem respeito à maneira como uma dada cultura lida com certos aspectos da vida, geralmente de natureza religiosa, filosófica e ética, dentre outros.

Não obstante, observa-se nas teorias de Jung uma complexidade ímpar, tanto no que diz respeito aos sonhos quanto no restante de sua teoria em geral. É evidente, sob certo ponto de vista, o quanto ela oscila ora abrindo-se a novas e amplas perspectivas, ora mostrando-se enclausurada em uma tradição mentalista, centrada no indivíduo e diluindo as questões sociais e políticas. Nesse sentido, uma apreciação mais acurada deve ser feita, uma maior investigação das teses de Jung e dos pós-junguianos por parte da academia, não só para que seu trabalho e outras posições teóricas se tornem mais conhecidas, mas para que se possa fazer uma análise crítica dele à luz das questões contemporâneas.

\section{A tecnologia dos sonhos dos WARLPIRI}

Longe dos propósitos decifratórios ou mentalistas das tradições europeias, encontra-se a tecnologia dos sonhos dos Warlpiri da Austrália. Para eles (GLOWCZEWSKI, 1987), o sonho não reitera a individualidade, mas compõe a cartografia da cultura, das instituições, dos anseios, dos interditos, dos seus itinerários e do seu território de viagens.

A cada manhã, os Warlpiri "relatam uns aos outros seus sonhos, gerindo sua produção onírica de maneira coletiva" (GLOWCZEWSKI, 1987, p. 44). De modo concreto, eles se reúnem diariamente para contar, desenhar na areia, dançar, pintar nos corpos os traços dos seus sonhos e suas perspectivas em um ritual que dá ensejo a uma técnica de gestão do seu cotidiano e constituição do seu território existencial. Os itinerários a serem percorridos concretamente pela tribo ocorrem em seus sonhos. Estes não remetem a um desejo recalcado, nem a um tempo das origens, mas à condição de todas as transformações possíveis. 
O tempo do sonho é o presente, não um tempo histórico, mas um tempo no qual todas as formas, o passado e o futuro, existem no presente, um tempo que está todo aí. O sonho não fala de nenhuma forma particular, de nenhum tempo particular, mas fala da dinâmica da transformação, das metamorfoses (GLOWCZEWSKI, 1987). Território "do passado, do presente e do futuro, no sonho estão estocadas todas as combinações possíveis dos elementos da existência [...] o sonho é todo o possível" (GLOWCZEWSKI, 1987, p. 16-17), o meio, a condição da vida, o ponto de origem da existência e de seu sentido. Pode-se dizer que o sonho tem um sentido cósmico.

Tendo esse viés, fazendo a gestão coletiva dos sonhos, até os deslocamentos cotidianos parecem expressar um estado onírico, e isso torna ainda mais explícito uma coalescência entre o sonho e a vida cotidiana. Sonhos de animais, pássaros, plantas, água, mulher solteira, pai incestuoso; constelação de sonhos ou de um sonho dentro do outro; sonhos que são referências de indivíduo ou território. Tudo o que existe tem seu sonho. A relação com os ancestrais e com a morte, com a vida e com o nascimento passa pelos sonhos; deles, tudo ou quase tudo provém e a eles retorna. Tudo pode se combinar com tudo e formam-se novas possibilidades.

Mas é interessante notar que isso tudo passa ou se submete à aceitação do grupo, que decide o que fazer: se faz pinturas corporais, se entoa cantos, dançar. Nas pinturas, por exemplo, sonhos diferentes podem ensejar o mesmo motivo; os elementos de um motivo decomposto podem ter o sentido de uma impressão animal, uma mulher sentada, um campo, uma nuvem; ou motivos diferentes podem vir do mesmo sonho: um motivo videira ou rio. O motivo não necessariamente aparece no sonho, embora outras vezes possa haver exclusão. Há nisso uma supremacia da dimensão pragmática, levando em conta ainda que não é do interesse dos Warlpiri dar significado às conexões dos sonhos, mas vivê-los em seu sentido não-significante. $\mathrm{O}$ importante não é que o sonho seja dito, nem explicado, nem que seja buscado um sentido oculto, mas que seja "vivido por cada indivíduo e o conjunto do grupo" (GLOWCZEWSKI, 1987, p. 19) corporalmente. O sonho não é uma medida, nem o logos, nem traz uma verdade, pois ele é produção, experimentação produtiva. É no corpo que o sentido disso tudo repousa, e o corpo existe dançando, cantando ou como corpo pintado, que assim o é para marcar na pele a força vital do sonho, não para representá-lo.

Os Warlpiri recusam o termo mítico dos etnólogos europeus para as suas descrições dos sonhos. Devemos entender o sonho não como relato mítico, mas como um território que, diríamos, cartografa itinerários virtuais, invisíveis aos nossos olhos, e atuais, visíveis, ambos territórios reais da experiência. Quando os aborígines recusam o termo mito, rejeitam o corte clássico, diz-nos Glowczewski (1987), entre a zona da realidade e a zona das aparências, mesmo que haja marcas de diferença e que existam limites. Essa concepção mantém uma interessante indiscernibilidade entre o plano do sonho e o da realidade (PELBART, 2000). O sonho não é etéreo, nem imaginário, nem subjetivo, porém, tão importante quanto o nomadismo real da comunidade. Permitiu aos Warlpiri assimilarem o espaço "moder- 
no" sedentário trazido pelo homem-branco, permitiu a comunicação de civilizações distintas, e seu retorno à cena do combate pela sua existência (GLOWCZEWSKI, 1987). Esse povo, acossado pela civilização branca, quase chegou a desaparecer.

É com essa tecnologia dos sonhos que os Warlpiri constituem territórios e arranjos existenciais. Arranjos, formas, nomes, itinerários e cartografias que não são inventados do nada, posto que tudo se dá no sonho; nem copiados de algo já existente, pois sempre se parte do zero na efetuação da lembrança do sonho. É com essa tecnologia que, sob o constrangimento imposto pelo colonizador branco, pelo sedentarismo da cultura branca, eles, ameaçados de desaparecimento, retomam suas viagens, renomadizam sua existência, assimilam parte da nova cultura e assim podem sobreviver e viver. O sonho tem o poder de liberar novos trajetos, novos destinos, novos futuros.

\section{Conclusão}

As tecnologias dos sonhos são práticas de condução de si e da cidade ou da cultura, como é explícito em Artemidoro e nos Warlpiri, mas que também podemos desvelar em Freud e Jung, nos casos de ajuste dos conflitos na urbe, para os quais a experiência de si enquanto indivíduo é mais relevante. Em um sentido um pouco mais amplo, diremos: as tecnologias dos sonhos auxiliam a trazer ao homem a responsabilidade de sua própria conduta. A partir disso podemos dizer que no contexto contemporâneo, as abordagens do mundo onírico adequam-se às tecnologias liberais de governo da cidade, como o método de Freud e o de Jung.

A psicologia, tomada aqui no olhar da psicanálise e da psicologia analítica, pode neutralizar o sonho ao extraí-lo do espaço social, petrificando-o e esvaziando-o de sua participação no drama urbano moderno, político, no qual nos inserimos, e mesmo ao deixar de ver nele os sinais da agonística existencial e cósmica.

Não obstante, é inegável a percepção do pai da psicanálise de que o sonho não é ilusão, de que ele é um evento resultante de um trabalho, embora de um pensamento (inconsciente) do qual o sujeito está apartado. Vale a pena lembrar que Freud vê uma relação entre os pensamentos oníricos e os pensamentos familiares da vida desperta. Durante o dia claro, os processos oníricos não estancam, ao contrário, se originam durante o dia, embora tenham a propriedade de passarem despercebidos (FREUD, 1987[1900]). Temos de concluir daí, mas isso não é nenhum assombro na psicanálise, que haja dois fluxos distintos e independentes de pensamentos durante o dia. Apesar de ter uma conotação unidirecional, da vida diurna para a noite, fica evidente que os sonhos mantêm relação estreita com o que se passa sob a claridade do dia e no terreno urbano.

Em Jung, tal relação - fluxos distintos de pensamento, consciente e inconsciente - fica menos apartada e ganha ares de uma complementariedade, embora com modos de funcionamento distintos (JUNG, 2002). De certa forma, sua questão é como integrá-los nos processos psíquicos vivenciados ao longo de uma vida. No caso, as experiências oníricas são tão importantes quanto as experiência de vigília, pois nos trazem outra maneira de ver as coisas, de se relacionar com 
as pessoas, enfim, de se conduzir no mundo. Entretanto, de certa forma, o campo político e social aparecem aqui apenas como um pano de fundo onde se encena o embate existencial de cada indivíduo.

Em Freud, como em Artemidoro, a imagem dos sonhos nunca se afirma a si mesma como experiência, pois sempre quer dizer outra coisa. Todavia, enquanto para o grego o sonho se torna assunto do povo, para o primeiro interessa exclusivamente ao indivíduo. Ao passo que, em Artemidoro, o universo prático e empírico da existência - envolvendo o social, o político, a natureza e o cosmos se estende aos processos oníricos, permitindo prever os acontecimentos futuros, para Freud são pensamentos diurnos que coincidem com os sonhos (FREUD, 1976[1922]). Enquanto o onirocrítico grego se mantinha no campo experimental da conduta, a vocação de Freud e Jung para o campo mental é inequívoca.

Todas essas tecnologias de sonhos apresentadas, embora distintamente, se coadunam às questões sociais de sua época, 3 uma no mundo antigo, as outras duas na Europa moderna, e a terceira no mundo atual, em um povo particular, e fazem parte do esforço valoroso de dar-lhes respostas. Subsumir a dramática urbana e civilizatória como dramática interior e individual é tornar possível uma intervenção cirúrgica cuja eficácia nos leva a acreditar que o fundamental da vida acontece na mente ou na consciência individual. Nessa mesma esteira, encontra-se, ao menos em parte, a psicologia analítica.

De outra feita, temos diante de nós uma tecnologia que se abre à prática gestionária dos sonhos, que é imediata e explicitamente coletiva: a tecnologia dos Warlpiri. Tecnologia para reinventar os itinerários, a percepção do que se deve fazer, de como se deve conduzir e do que deve existir. O potencial de transformação dos sonhos e as técnicas de gestão dos Warlpiri nos permitem querer elaborar práticas e encontros que reativem a potência coletiva da vida e, ao mesmo tempo, esse coletivo possa liberar forças políticas de transformação de si e do mundo. Devido ao isolamento do indivíduo cada vez mais acentuado, assim como a angústia de existir da qual fala Norbert Elias (1994), é imprescindível que as ciências humanas proponham arranjos e práticas de uma gestão da vida que nos resguarde desse isolamento. A reativação dos elementos instituintes dos sonhos (SANTOS, 2010), elementos transformadores dos valores e modos de relação, poderia retornar como uma maior força de invenção de modos de viver e de criação de novos arranjos sociais para as pessoas na atualidade? Qual processualidade aí emerge que imprime mudanças aos modos de vida do dia claro? A produção daí decorrente pode nos permitir dar consistência a uma prática de gestão coletiva dos sonhos no seio do espaço urbano e constituir-se como prática de formação subjetiva capaz de responder às questões sociais contemporâneas? Essas perguntas são abertas a nós e se infundem a partir da leitura das tecnologias dos sonhos que procedemos. E nossa leitura inclina-nos a considerar a construção de uma tecnologia dos sonhos capaz de liberar novos itinerários e novos futuros (SANTOS, 2010), como o que chamamos de gestão coletiva dos sonhos, mas que será apresentado em outra ocasião. 


\title{
Notas
}

\begin{abstract}
${ }^{1}$ Para oreinen e to on eirei, temos duas versões. Na tradução brasileira, na obra $A$ História da Sexualidade: o cuidado de si, de Michel Foucault (2009, p. 19), é 'modificam a alma' e 'o que diz o ser', respectivamente. E na tradução de Eliana Aguiar da obra de Artemidoro do francês para o português, é 'pôr a alma em movimento' e 'diz o que é' (ARTEMIDORO, 2009, p. 22).

${ }^{2}$ Uma das posições de Jung acerca dos sonhos se aproxima desta. Um alpinista lhe conta um sonho debochando da sua capacidade de interpretação. Jung lhe dá um aviso: "A partir de hoje, escale na companhia de um guia" (JUNG, 1999, p. 22). O homem, incrédulo das palavras do mestre, sofreu um acidente meses depois, escalando sozinho, e morreu.

${ }^{3}$ Foucault é da opinião de que os séculos I e II da nossa era, quando viveu Artemidoro, são o período de ouro de uma cultura de si baseada na experiência, nos erros, na correção das condutas, mais que no conhecimento de si (FOUCAULT, 2009).
\end{abstract}

\section{REFERÊNCIAS}

ALSCHULER, L. R. Jung e política. In: YOUNG-EISENDRATH, P.; DAWSON, T. (Org.). Manual de Cambridge para estudos junguianos. Porto Alegre: Artmed, 2002. p. 261-272.

ARTEMIDORO. Sobre a interpretação dos sonhos. Rio de Janeiro: J. Zahar, 2009.

DOUGLAS, C. O contexto histórico da psicologia analítica. In: YOUNGEISENDRATH, P.; DAWSON, T. (Org.). Manual de Cambridge para estudos junguianos. Porto Alegre: Artmed, 2002. p. 41-54.

ELIAS, N. A Sociedade dos indivíduos. Rio de Janeiro: J. Zahar, 1994.

FIGUEIREDO. L. C. A Invenção do psicológico. São Paulo: Escuta/Educ, 1994.

FOUCAULT, M. História da Loucura. São Paulo: Perspectiva, 1989.

FOUCAULT, M. Sonhar com os próprios prazeres. In: . História da Sexualidade: o cuidado de si. São Paulo: Graal, 2009. v. 3, p. 09-42.

FREUD, S. Construções em análise (1937). In:

Rio de Janeiro: Imago, 1975. v. XXIII, p. 289-304. . Obras Completas. [1937]

FREUD, S. Dois verbetes de enciclopédia (1922). In: . Obras Psicológicas Completas de Sigmund Freud. Rio de Janeiro: Imago, 1976. Edição Standard Brasileira, v. 18, p. 285-318.

FREUD, S. Totem e Tabu (1912). In___ : Obras Psicológicas Completas de Sigmund Freud. Rio de Janeiro: Imago, 1996. Edição Standard Brasileira, v. 13, p. 13-163. 
FREUD, S. A interpretação dos sonhos (1900). In: . Obras Psicológicas Completas de Sigmund Freud. Rio de Janeiro: Imago, 1987. Edição Standard Brasileira, v. 7, p. 11-650.

GLOWCZEWSKI, B. Les Warlpiri. Revue Chimères, n. 1. Paris: Dominique Bedou, 1987.

JUNG, C. G. Ab-reação, análise dos sonhos, transferência. Petrópolis: Vozes, 1999.

JUNG, C. G. O Eu e o inconsciente. Petrópolis: Vozes, 2002.

LAPLANCHE, J.; PONTALIS, J.-B. Vocabulário de Psicanálise (Conteúdo latente). São Paulo: Martins Fontes, 1988.

MAIA NETO, J. J. O Manejo dos Sonhos: um estudo sobre símbolos na psicologia analítica. 2010. Monografia (Especialização) - Faculdade de Psicologia, Unidade de Ensino Superior Ingá, Maringá, 2010.

PELBART, P. P. Cidade, lugar do possível. In: . A vertigem por um fio. São Paulo: Iluminuras, 2000. p. 43-49.

SAMUELS, A. Introdução: Jung e os pós-junguianos. In: YOUNGEISENDRATH, P.; DAWSON, T. (Org.). Manual de Cambridge para estudos junguianos. Porto Alegre: Artmed, 2002, p. 27-37.

SANTOS, A. O. Gestão coletiva dos sonhos: elementos para uma psicologia da diferença. Mnemosine, Rio de Janeiro, v. 6, n. 2, p. 59-76, 2010.

SARTRE, J.-P. A Imaginação. Porto Alegre: LPM, 2010.

Recebido em: 28 de outubro de 2012 Aceito em: 23 de abril de 2014 
